\title{
DoE/PC/92110--T/5
}

QUARTERLY TECHNICAL PROGRESS REPORT 12 JANUARY-MARCH, 1996

\section{DEVELOPMENT OF VANADIUM-PHOSPHATE CATALYSTS FOR METHANOL PRODUCTION BY SELECTIVE OXIDATION OF METHANE}

\author{
Prepared for \\ Arun C. Bose (Technical Project Officer) \\ U.S. Department of Energy \\ Pittsburgh Energy Technology Center \\ Pittsburgh, PA 15236
}

\author{
By \\ Robert L. McCormick (Principal Investigator) \\ Gokhan O. Alptekin (Graduate Assistant) \\ Department of Chemical Engineering and Petroleum Refining \\ and \\ Colorado Institute for Fuels and High-Altitude Engine Research \\ Colorado School of Mines \\ Golden, Colorado 80403-1887
}

DOE Contract No. DE-AC22-92PC92110

Contract Date: October 1, 1992

Anticipated Completion Date: March 31, 1997

Government Award For Current Fiscal Year: \$125,496

Final

June 27, 1996

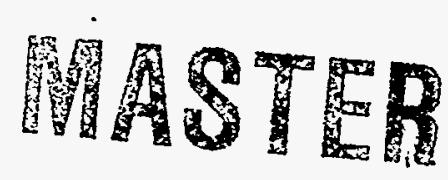

DISTRIBUTION OF THIS DOCURENT IS UNLIMITED

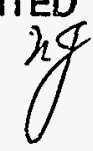




\section{DISCLAIMER}

Portions of this document may be illegible in electronic image products. Images are produced from the best available original document. 


\section{EXECUTIVE SUMMARY}

This document is the twelfth quarterly technical progress report under Contract No. DE-AC22-92PC92110 "Development of Vanadium-Phosphate Catalysts for Methanol Production by Selective Oxidation of Methane". Activities focused on acquisition of kinetic data for oxidation of formaldehyde and methanol on these catalysts. In the next quarter these results will be used to propose a simple reaction network and kinetic model. A strategy for publishing the results of this contract in refereed journals is also outlined.

To date we have completed Task 1: Laboratory Setup and Task 2: Process Variable Study. Activities in the current quarter focused on finalizing these tasks and on Task 3: Promoters and Supports, this task is approximately $50 \%$ completed. Task 4: Advanced Catalysts is to be initiated in the next quarter. Specific accomplishments this quarter include:

- Finalizing and calibrating a new reaction product analytical system with markedly improved precision and accuracy relative to older approaches.

- Development of procedures for accurately feeding formaldehyde to the reactor.

- Examination of formaldehyde and methanol oxidation kinetics over vanadyl pyrophosphate at a range of temperatures.

- Preliminary studies of methane oxidation over a silica support.

\section{DISCLAIMER}

This report was prepared as an account of work sponsored by an agency of the United States Government. Neither the United States Government nor any agency thereof, nor any of their employees, makes any, warranty, express or implied, or assumes any legal liability or responsibility for the accuracy, completeness, or usefulness of any information, apparatus, product, or process disclosed, or represents that its use would not infringe privately owned rights. Reference herein to any specific commercial product, process, or service by trade name, trademark, manufacturer, or otherwise does not necessarily constitute or imply its endorsement, recommendation, or favoring by the United States Government or any agency thereof. The views and opinions of authors expressed herein do not necessarily state or reflect those of the United States Government or any agency thereof. 


\section{TABLE OF CONTENTS}

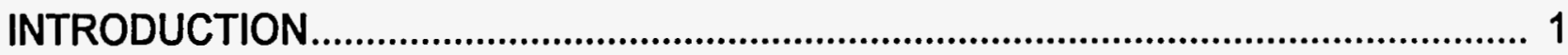

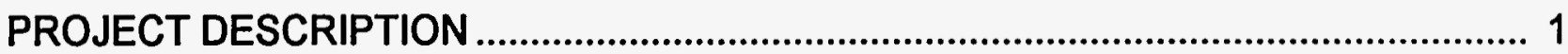

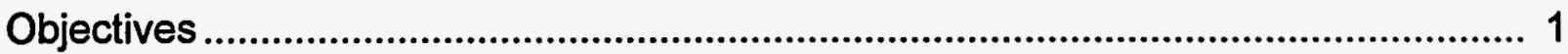

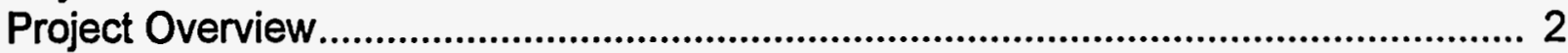

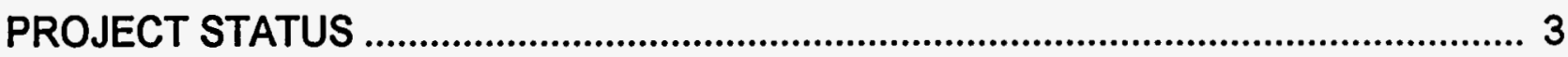

Product Gas Analysis/Calibration .............................................................................. 3

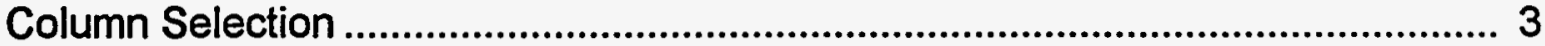

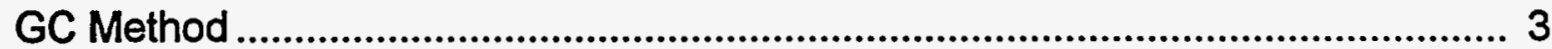

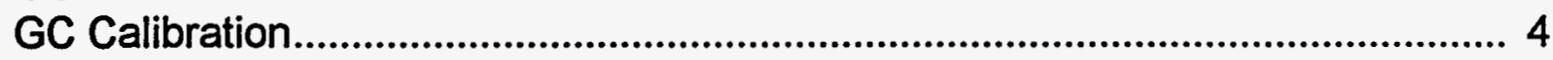

Feed System for Methanol and Formaldehyde.................................................. 6

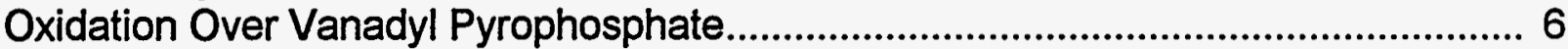

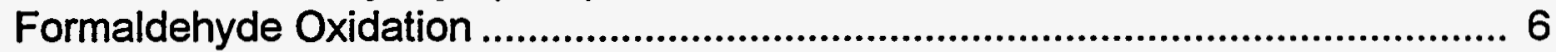

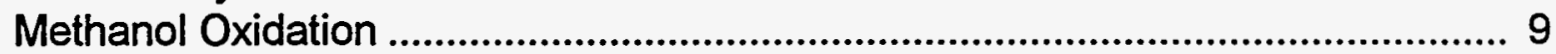

Oxidation Over Silica Supported Vanadyl Pyrophosphate ........................................... 11

Supported Catalyst Preparation .............................................................................. 11

Methane Oxidation Over Silica Support ................................................................... 11

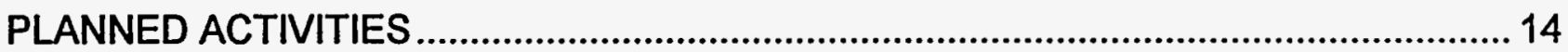

Methane Oxidation/Vanadyl Pyrophosphate (Revisited) ............................................ 14

Methane Oxidation/Silica Supported Catalysts........................................................... 14

Methane Oxidation/Promoted Catalysts ................................................................ 14

Methane Oxidation/Iron Phosphate Catalysts....................................................... 14

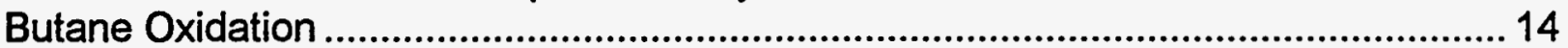

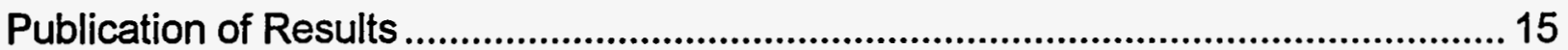

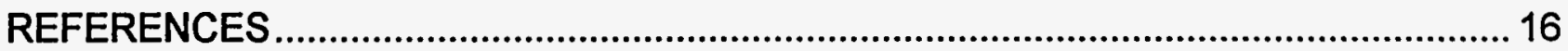




\section{LIST OF FIGURES}

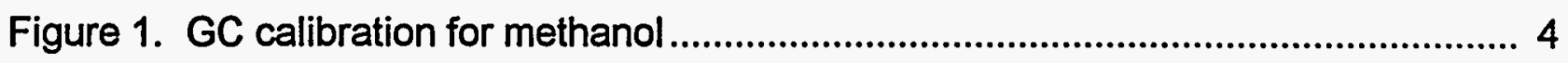

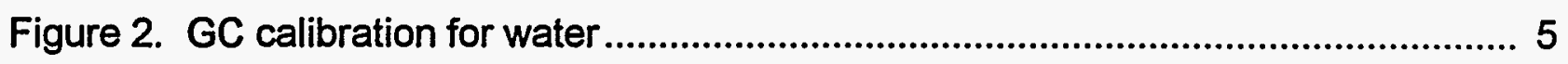

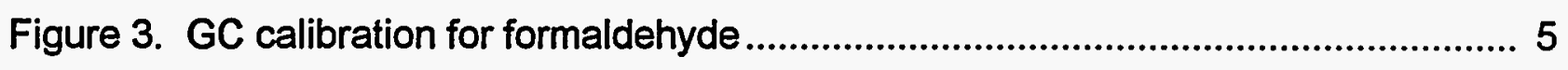

Figure 4. Vapor phase formaldehyde concentration (as GC area count) versus paraformaldehyde decomposition/vaporization temperature ........................................... 6

Figure 5. Effect of temperature on formaldehyde conversion over vanadyl pyrophosphate .................................................................................................................. 7

Figure 6. Arrhenius plot for formaldehyde oxidation over vanadyl pyrophosphate.......... 8

Figure 7. Selectivity as a function of conversion for formaldehyde oxidation ................. 8

Figure 8. Effect of temperature on methanol conversion over vanadyl pyrophosphate ................................................................................................................. 9

Figure 9. Arrhenius plot for methanol oxidation over vanadyl pyrophosphate .................. 10

Figure 10. Selectivity as a function of conversion for methanol oxidation ...................... 10

Figure 11. Effect of temperature on methane conversion over precipitated silica ........... 12

Figure 12. Arrhenius plot for methane oxidation over precipitated silica support ............ 12

Figure 13. Selectivity as a function of conversion for methane oxidation over precipitated silica support 


\section{INTRODUCTION}

This document is the twelfth quarterly technical progress report under Contract No. DE-AC22-92PC92110 "Development of Vanadium-Phosphate Catalysts for Methanol Production by Selective Oxidation of Methane". The basic premise of this project is that vanadyl pyrophosphate (VPO), a catalyst used commercially in the selective oxidation of butane to maleic anhydride, can be developed as a catalyst for selective methane oxidation. Data supporting this idea include published reports indicating moderate to high selectivity in oxidation of ethane (Michalakos, et al., 1993), propane (Ai, 1986), and pentane (Busca and Centi, 1989 ), as well as butane (Centi, et al., 1988). Methane oxidation is a much more difficult reaction to catalyze than that of other alkanes and it is expected that considerable modification of vanadyl pyrophosphate will be required for this application. It is well known that VPO can be modified extensively with a large number of different promoters and in particular that promoters can enhance selectivity and lower the temperature required for butane conversion (Hutchings, 1991).

Additionally, it has been shown that strong Lewis acid sites on the surface of VPO are responsible for initial alkane activation (Busca, et al., 1986a). This Lewis acidity is thought to be caused by lattice defects or strain initiated by disorder in stacking of the layers of VPO (Busca, et al, 1986b; Horowitz, et al, 1988). One approach we have taken is directed at increasing the strength of these strong Lewis acid sites by enhanced strain or disorder in the layer stacking. Surface acidity was measured by FTIR of chemisorbed bases. By increasing Lewis acid site strength it is hoped that the temperature required for methane activation can be lowered resulting in improved selectivity. Other approaches include modification of VPO with promoters or by dispersion on supports. The effect of including reductants, such as butane, or oxidants, such as hydrogen peroxide, in the feed gas will also be examined. In this report we describe results of a kinetic study where methanol and formaldehyde were oxidized over VPO. Preliminary work with a silica support is also described along with a procedure for preparation of silica supported VPO. Plans for future quarters are described.

\section{PROJECT DESCRIPTION}

\section{Objectives}

The specific objectives of this project are:

- To develop an economical catalyst for partial oxidation of methane to methanol.

- To determine optimum conditions for methanol production from methane using VPO catalysts. In particular to determine the effect of lean conditions (excess oxygen), oxygen deficient conditions (used in most other methane oxidation studies), and the potential of using the catalyst as a stoichiometric oxidant or oxygen carrier. 
- To utilize promoters and catalyst supports to improve oxygenate yield relative to the base case catalysts.

- To provide a preliminary understanding of how these promoters and supports actually effect catalyst properties.

- Use the information obtained to prepare advanced catalysts which will be tested for activity, selectivity, and stability.

\section{Project Overview}

The goal of the project is to develop a catalyst which allows methane oxidation to methanol to be conducted at high conversion and selectivity. Ideally, a low $\mathrm{CH}_{4} / \mathrm{O}_{2}$ ratio will be employed with air as the source of oxygen. The catalyst development strategy will be to utilize promoters and supports to improve the activity and selectivity of the unmodified VPO catalyst. Catalysts will be characterized by surface area measurement, elemental analysis, $x$-ray powder diffraction, FTIR, as well as pulsed and continuous reactivity/selectivity studies.

The project is divided into four tasks:

Task 1: Laboratory Setup. Equipment for catalyst preparation and reactivity testing will be set up and tested. Gas analytical procedures will be developed. Blank reactor runs will be conducted. Much of this task was accomplished during the first project year at Amax Research and Development but the work had to be repeated to restart the project at the Colorado School of Mines.

Task 2: Process and Catalyst Variable Study. Tests will be conducted to determine the optimum conditions of temperature, pressure, $\mathrm{CH}_{4} / \mathrm{O}_{2}$ ratio, $\mathrm{H}_{2} \mathrm{O} / \mathrm{CH}_{4}$ ratio, space velocity, and catalyst $\mathrm{P}: \mathrm{V}$ ratio for high activity and selectivity in methanol production. Several important aspects of this task have been completed and were reported in the topical report describing results acquired on this project at Amax Research and Development. A number of other experiments will be conducted in coming months.

Task 3: The Effect of Promoters and Supports. Several promoters and supports will be tested. The measured response will be activity and selectivity in the methane oxidation reaction to methanol. Catalyst characterization will provide a fundamental understanding of these effects. This work has been initiated in this area and many more catalyst should be prepared in the next quarter.

Task 4: Advanced Catalyst Testing. Advanced catalysts using the best ideas developed in previous tasks will be prepared. These catalysts will be tested in runs of relatively long duration to determine long-term activity, selectivity, and stability in methane oxidation to methanol. 


\section{PROJECT STATUS}

\section{Product Gas Analysis/Calibration}

Column Selection. The effluent gas stream from the methane oxidation reactor, which is operated in differential mode, contains unreacted methane and oxygen in large quantities, carbon monoxide, carbon dioxide, water, formaldehyde and methanol in trace amounts. Dimethyl ether and methyl formate are also possible reaction products. The effluent gas composition is measured on line using an HP5890 Gas Chromatograph (GC) equipped with a thermal conductivity detector. Due to their different chemical nature and physical characteristics, separation of these compounds in the gas chromatographic system is a difficult task. In the literature there are few research groups who try to separate these components by using one GC column. Previously, we also tried to achieve this separation with a 15 $\mathrm{ft}$ Carboxen column. Separation of peaks was very good for all gaseous components, but peaks were tailed and flat for methanol and formaldehyde.

The general approach described in the literature is to analyze the gaseous and liquid compounds using different columns. For gases, molecular sieve or carbon molecular sieve columns are used, which provides separation according to molecular size differences. For liquid samples porous polymer beads are used to provide sharp and symmetrical peaks and low retention volumes especially for water and alcohols. For analysis of oxygen, carbon monoxide, methane and carbon dioxide we selected a Carbosphere column. The packing material was developed by NASA for planetary entry probes in space exploration purposes where atmospheric composition is a highly important analysis. Carbosphere not only gives the highest resolution between oxygen and carbon monoxide but also elutes carbon monoxide at very low temperatures when compared with other carbon molecular sieve columns, which shortens analysis times notably. A Poropak-T column was selected to analyze for methanol, formaldehyde, water, dimethyl ether, methyl formate and carbon dioxide. Poropak-T column with EGDMA (ethylene glycol dimethacrylate) has the highest polarity and offers greatest water retention and gives the best separation between water and formaldehyde which is critical for the purpose of this analysis.

GC Method. A 6' x 1/8" S.S. Carbosphere 80/100 column and a 8' $\times 1 / 8^{\prime \prime}$ S.S. Porapak-T column are connected to a 6-port Valco valve which is operated manually for column selection. For Carbosphere column the $\mathrm{GC}$ temperature program starting at $50^{\circ} \mathrm{C}$ and ending at $130^{\circ} \mathrm{C}$ was applied, with an initial soak time of 3 minutes and a rate of $30^{\circ} \mathrm{C} / \mathrm{min}$. For the Porapak-T column the $\mathrm{GC}$ temperature was held constant at $130^{\circ} \mathrm{C}$.

Two 6-port Valco valves with 1.0 and $2.0 \mathrm{cc}$ sample loops and automatic air activation are used for sampling. The reactor effluent contains components in large quantities and trace quantities which makes quantification and detection very difficult if only one sampling valve is used. The valve box as well as all the effluent transfer lines are kept at $130^{\circ} \mathrm{C}$ to prevent any condensation. GC reference gas flow rate 
and column flow rate is set to $25 \mathrm{ml} / \mathrm{min}$ and $30 \mathrm{ml} / \mathrm{min}$ which gives optimum sensitivity and lowest pressure head through the column.

GC Calibration. Calibration for gaseous species $\left(\mathrm{CO}, \mathrm{CO}_{2}, \mathrm{CH}_{4}\right.$, dimethyl ether) was accomplished using calibration standards obtained from Scott Specialty Gases (Certified Master Gas). Methanol and water calibration was performed using standard solutions of reagent grade methanol and deionized water prepared by in volumetric flasks. These were injected with a $0.5 \mu \mathrm{L}$ syringe to obtain calibration curves which are shown in Figures 1 and 2. Calibration for formaldehyde is more complex. Paraformaldehyde was placed in a flask which was heated and purged by the feed gas. A feed gas of oxygen in helium was passed through this system and analyzed to obtain a formaldehyde peak area. The mixture was then passed over a $4 \mathrm{wt} \% \mathrm{Pd} / \mathrm{alumina}$ combustion catalyst at $400^{\circ} \mathrm{C}$. Carbon dioxide was the only combustion product. The known $\mathrm{CO}_{2}$ calibration was then used to determine the concentration of formaldehyde in the feed gas. This concentration and the formaldehyde peak area constitute a calibration curve for formaldehyde which is shown in Figure 3.

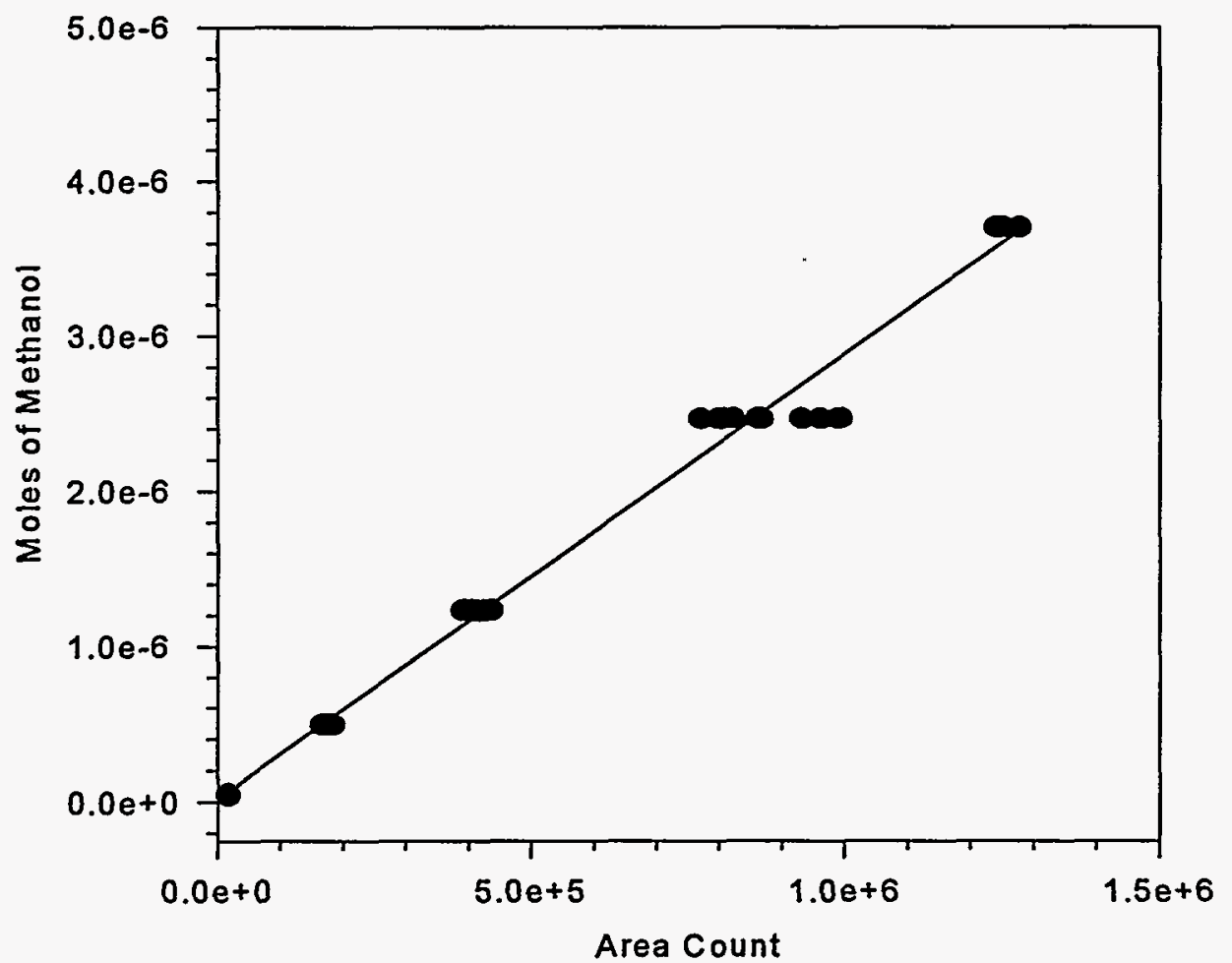

Figure 1. GC calibration for methanol. 


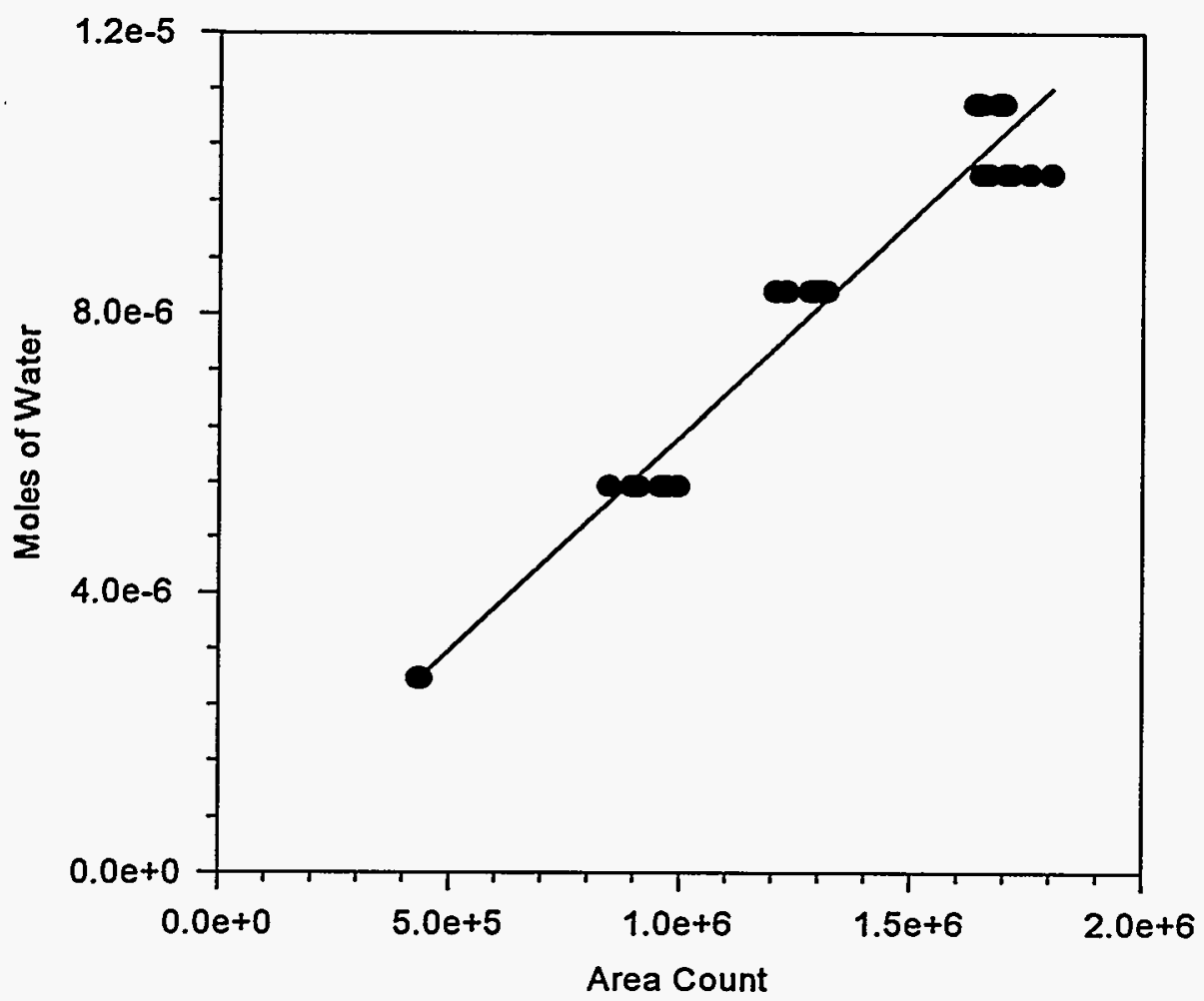

Figure 2. GC calibration for water.

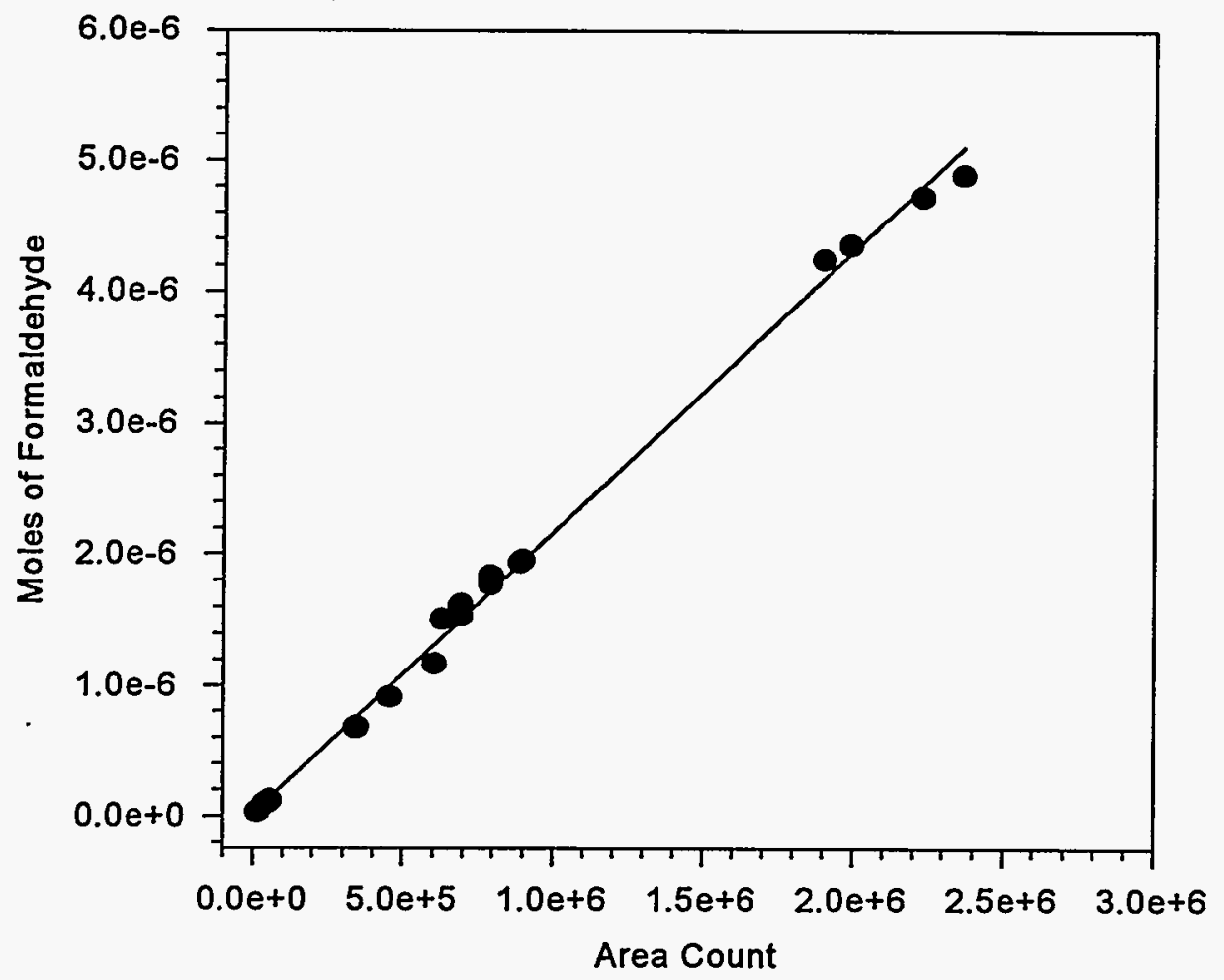

Figure 3. GC calibration for formaldehyde. 
Feed System for Methanol and Formaldehyde. Methanol was fed to the reactor by passing the feed gas through a series of two heated bubblers containing reagent grade methanol at room temperature. Formaldehyde was introduced into the feed gas using paraformaldehyde decomposition, in a manner identical to that used to generate the formaldehyde GC calibration curve. Control of the bubble temperature was reasonably accurate at producing a corresponding formaldehyde concentration, as shown in Figure 4. In all cases the feed gas was analyzed by GC to obtain the actual feed gas composition.

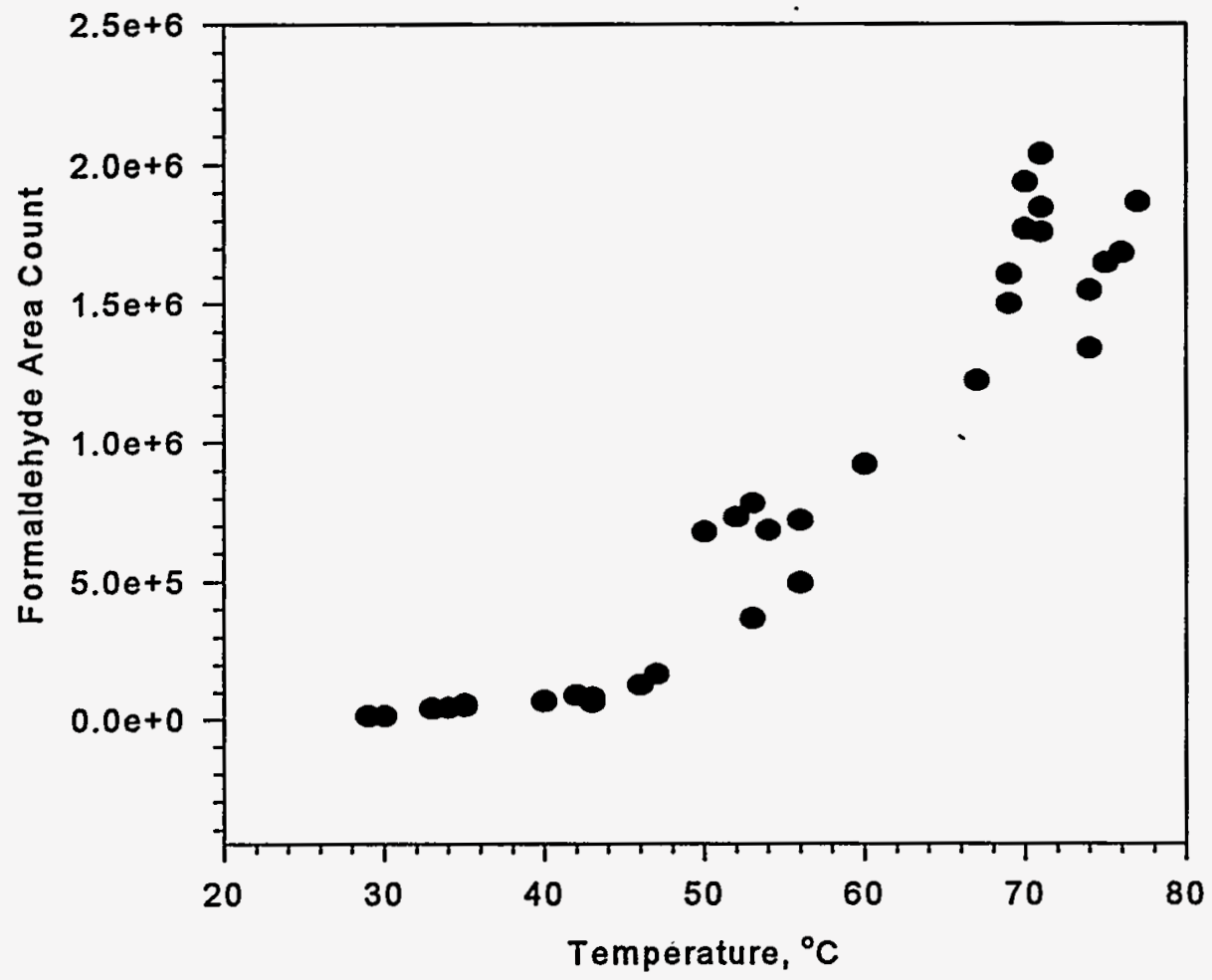

Figure 4. Vapor phase formaldehyde concentration (as GC area count) versus paraformaldehyde decomposition/vaporization temperature.

\section{Oxidation Over Vanadyl Pyrophosphate}

In previous reports we have described our results for methane oxidation over vanadyl pyrophosphate. We will briefly revisit this system using our new analytical system in the next quarter. In the present quarter we have examined the oxidation of methanol and formaldehyde over this catalyst. These results are described below.

Formaldehyde Oxidation. Oxidation of $\mathrm{HCHO}$ was examined at GHSV of 13,000 and over the temperature range of 200 to $425^{\circ} \mathrm{C}$. An $\mathrm{O}_{2}$ to $\mathrm{CO}$ molar ratio of 20 was used for all experiments ( 1.2 mole\% $\mathrm{HCHO}$ in feed). Carbon balances for most runs closed with in $2 \%$, for all runs the carbon balance closed within $7 \%$. The effect of temperature on conversion is plotted in Figure 5. An Arrhenius plot was prepared for runs having conversion of $12 \%$ or lower (below $260^{\circ} \mathrm{C}$ ) and is shown in Figure 6. 
The plot is highly linear $\left(r^{2}=.99\right)$ and yields an activation energy for formaldehyde oxidation of $17.2 \pm 1.0 \mathrm{kcal} / \mathrm{mole}$ for formaldehyde oxidation (error range is standard error). Carbon oxides were the only reaction products observed in formaldehyde oxidation. Figure 7 shows selectivity to these products as a function of conversion. The results strongly suggest that formaldehyde is converted to $\mathrm{CO}$ which is in turn converted to $\mathrm{CO}_{2}$ via a consecutive reaction.

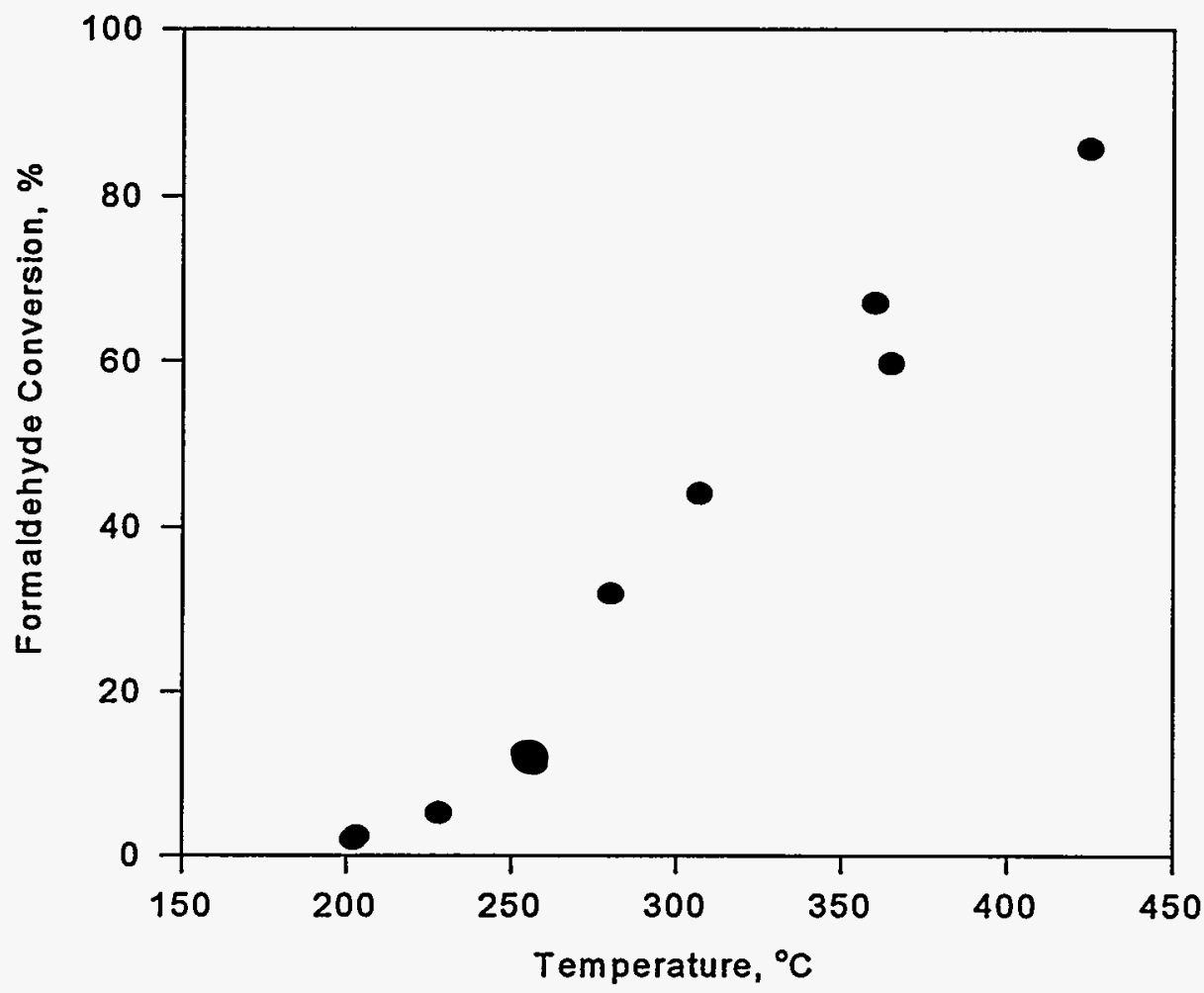

Figure 5. Effect of temperature on formaldehyde conversion over vanadyl pyrophosphate. 


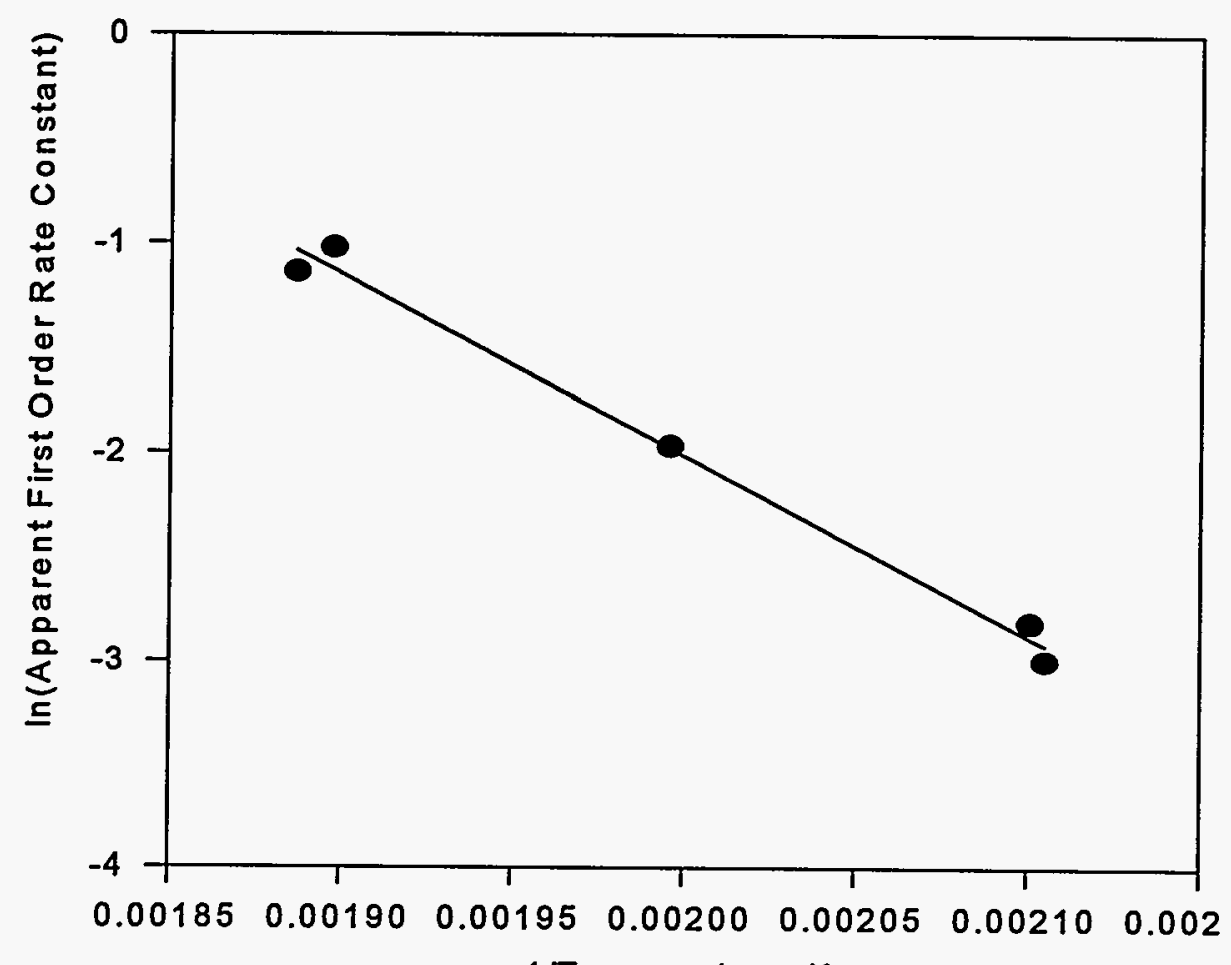

Figure 6. Arrhenius plot for formaldehyde oxidation over vanadyl pyrophosphate.

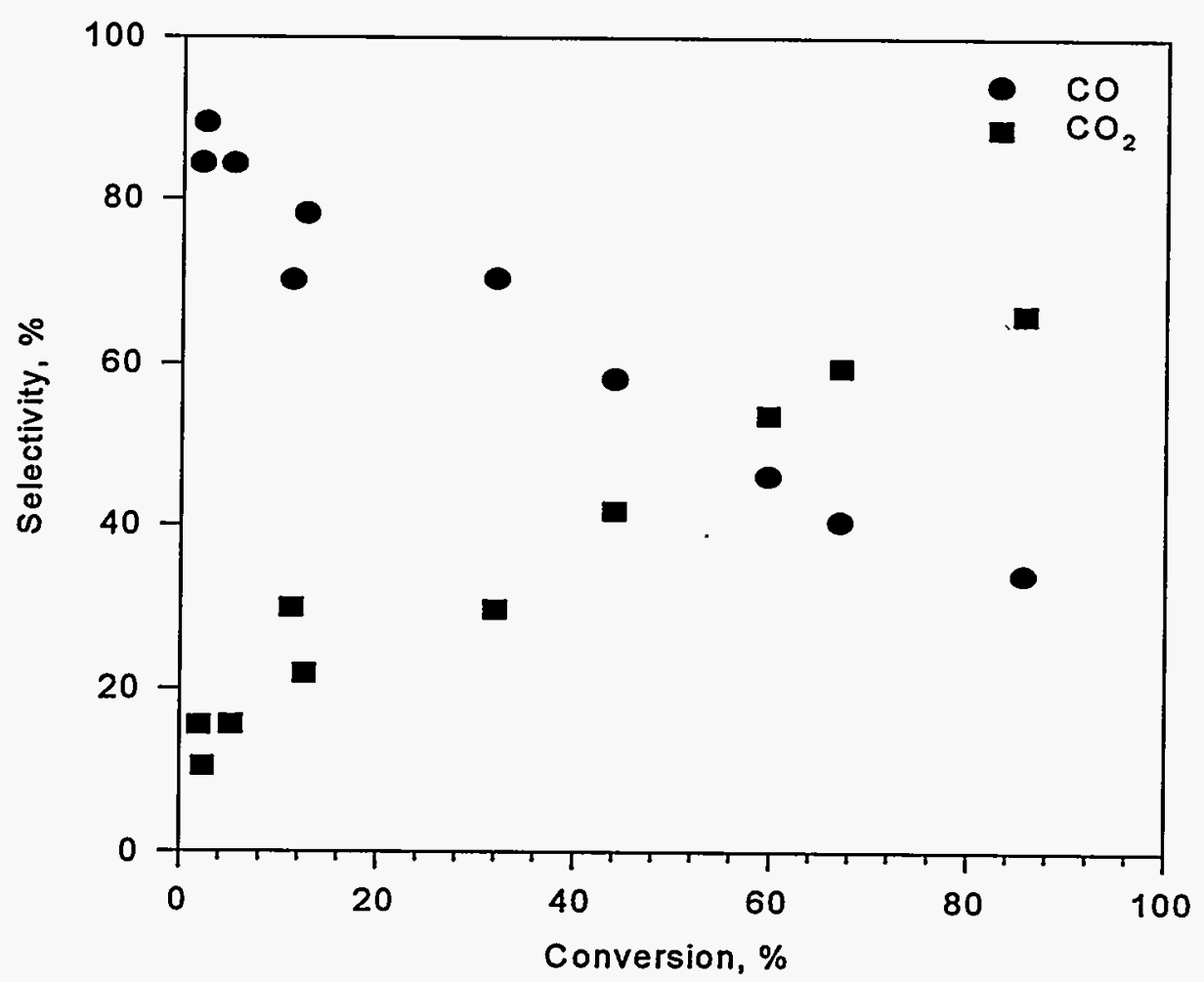

Figure 7. Selectivity as a function of conversion for formaldehyde oxidation. 
Methanol Oxidation. Oxidation of methanol was examined at GHSV of 13,000 and over the temperature range of 150 to $400^{\circ} \mathrm{C}$. An $\mathrm{O}_{2}$ to methanol molar ratio of 4 was used for all experiments ( 8.9 mole\% methanol). Carbon balances for closed with in $2 \%$ for all runs. The effect of temperature on conversion is plotted in Figure 8 . An Arrhenius plot was prepared for runs having conversion of $10 \%$ or lower (below $\left.275^{\circ} \mathrm{C}\right)$ and is shown in Figure 9 . The plot is highly linear $\left(r^{2}=.99\right)$ and yields an activation energy for formaldehyde oxidation of $16.4 \pm 0.2 \mathrm{kcal} / \mathrm{mole}$ for methanol oxidation. Dimethyl ether (DME), formaldehyde, $\mathrm{CO}$, and $\mathrm{CO}_{2}$ were observed as reaction products. Dimethyl formate was not observed. Selectivity to these products as a function of conversion is shown in Figure 10. Note that DME selectivity is initially at $100 \%$. As conversion increases additional products are observed, first formaldehyde then $\mathrm{CO}$ followed by $\mathrm{CO}_{2}$. These selectivities strongly suggest $\mathrm{a}$ sequential reaction mechanism of the form:

$$
\mathrm{CH}_{3} \mathrm{OH} \longrightarrow \mathrm{CH}_{3} \mathrm{OCH}_{3} \longrightarrow \mathrm{CH}_{2} \mathrm{O} \longrightarrow \mathrm{CO} \longrightarrow \mathrm{CO}_{2}
$$

The results reported above for formaldehyde oxidation are consistent with the last two reactions of this simple scheme.

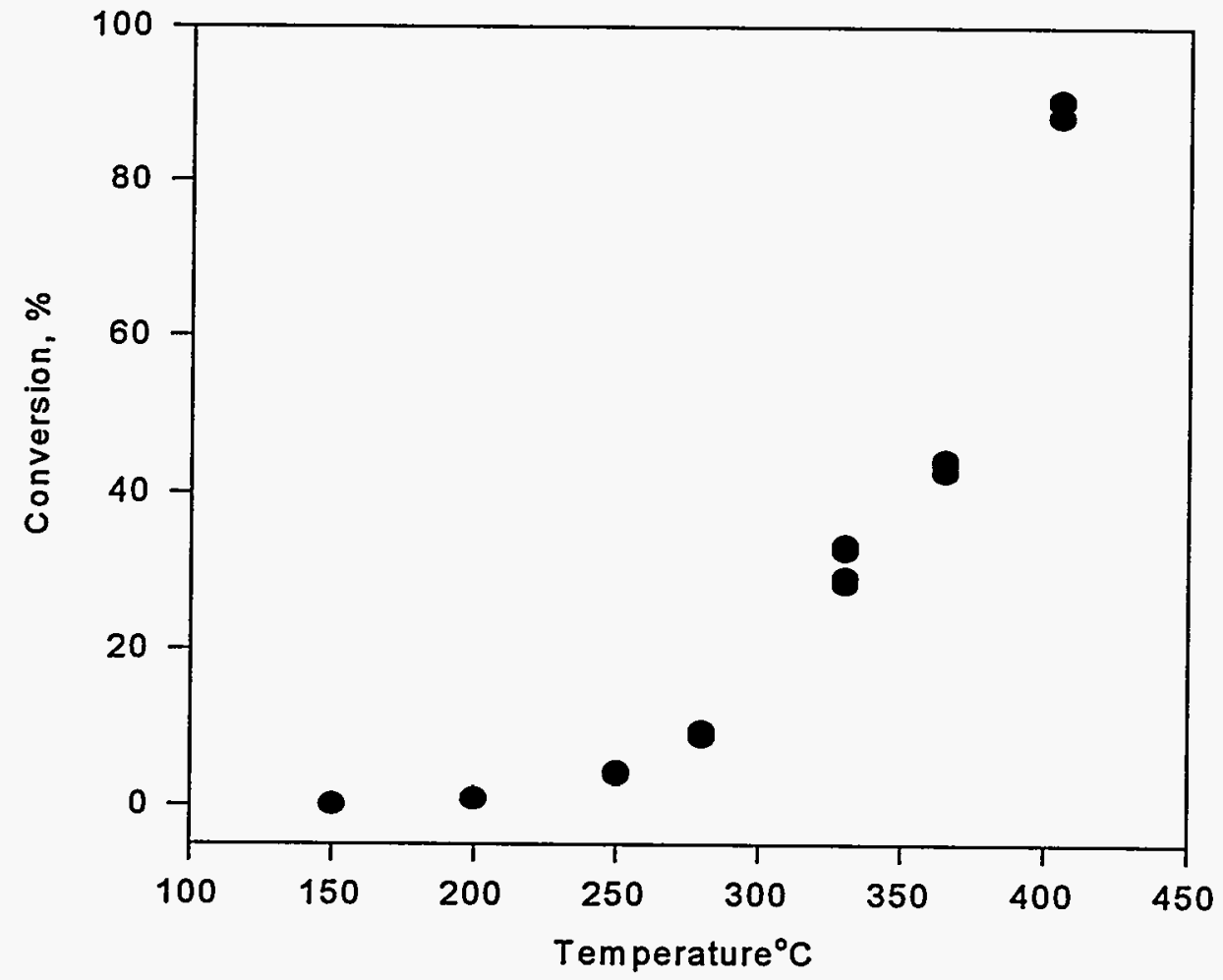

Figure 8. Effect of temperature on methanol conversion over vanadyl pyrophosphate. 


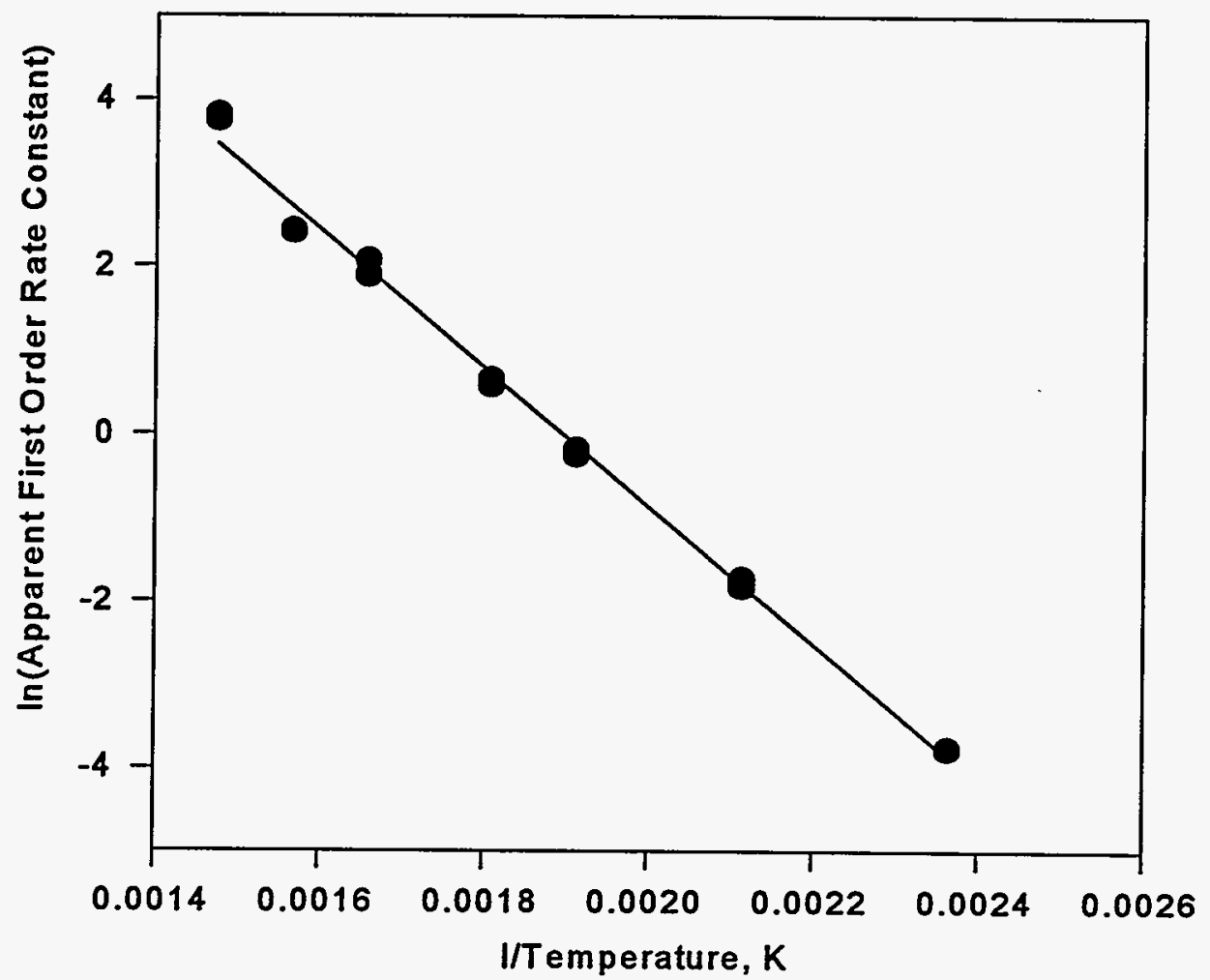

Figure 9. Arrhenius plot for methanol oxidation over vanadyl pyrophosphate.

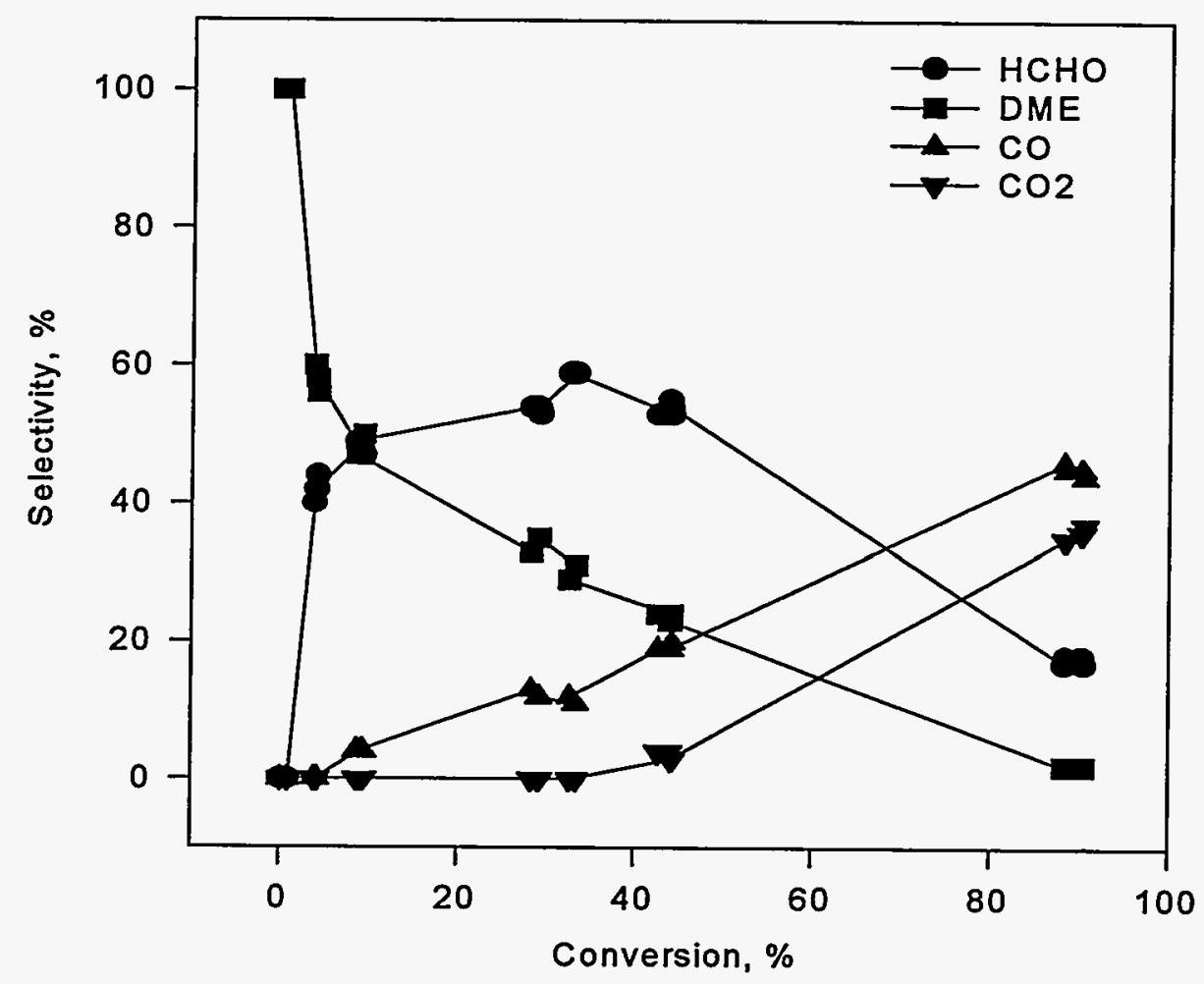

Figure 10. Selectivity as a function of conversion for methanol oxidation. 


\section{Oxidation Over Silica Supported Vanadyl Pyrophosphate}

Supported Catalyst Preparation. Recently Miyake and Doi (1995) have presented the results of a study of the preparation of vanadyl pyrophosphate. They show that the most active and selective preparations involve careful reduction of $\mathrm{V}_{2} \mathrm{O}_{5}$ to $\mathrm{V}_{4} \mathrm{O}_{9}$ followed by slow reaction with anhydrous phosphoric acid to form the catalyst precursor $\mathrm{VOHPO}_{4}-0.5 \mathrm{H}_{2} \mathrm{O}$. Their work suggests an approach for synthesis of vanadyl pyrophosphate on a support. The starting point for this synthesis is supported $\mathrm{V}_{2} \mathrm{O}_{5}$ prepared by conventional impregnation and calcining. This supported vanadia is then carefully reduced, using the isobutyl alcohol as described by Miyake and Doi, to produce silica supported $\mathrm{V}_{4} \mathrm{O}_{9}$. After filtration from the reaction mixture and resuspension in fresh solvent, anhydrous phosphoric acid dissolved in isobutyl alcohol is added dropwise to produce the precursor dispersed on the support. We are currently working on this approach to catalyst synthesis.

Methane Oxidation Over Silica Support. Parmaliana and coworkers (1991) have demonstrated that silica is an active catalyst for conversion of methane to formaldehyde at temperatures above $500^{\circ} \mathrm{C}$. A precipitated $\mathrm{SiO}_{2}$ was found to be more active than extruded, gel, or fumed samples with $\mathrm{HCHO}$ selectivities as high as $70 \%$ ( $\mathrm{HCHO}$ space time yield as high as $17 \mathrm{~g} / \mathrm{kg}_{\mathrm{cat}}-\mathrm{hr}$ ). Furthermore, the same group of researchers (Parmaliana, et al., 1994) has proposed that when vanadia or molybdena is added to silica they serve to promote the intrinsic activity of the silica. Thus, it seems important to determine the activity of our silica support.

The support material used in our work is a precipitated, acid washed silica. Acid washing reduces the $\mathrm{Na}$ content which was found to be beneficial in Parmaliana's work. Reaction conditions included temperatures up to $650^{\circ} \mathrm{C}, \mathrm{GHSV}$ of 3400 and two methane to oxygen ratios: 3 to 1 and 1 to 1 . Carbon balances closed within $2 \%$ for most runs and within $5 \%$ for all runs reported. The effect of temperature on methane conversion is shown in Figure 11. Significant conversion was not obtained below $500^{\circ} \mathrm{C}$. Methane to oxygen ratio had little effect on overall activity. An Arrhenius plot for the 1:1 ratio is shown in Figure 12. This plot yields an activation energy of $32.5 \pm 0.9 \mathrm{kcal} / \mathrm{mole}$. Formaldehyde and carbon oxides were the only reaction products observed. Selectivities as a function of conversion are plotted in Figure 13. The results imply a set of reactions in series:

$$
\mathrm{CH}_{4} \longrightarrow \mathrm{HCHO} \longrightarrow \mathrm{CO} \longrightarrow \mathrm{CO}_{2}
$$

These results are in qualitative agreement with the literature noted above. 


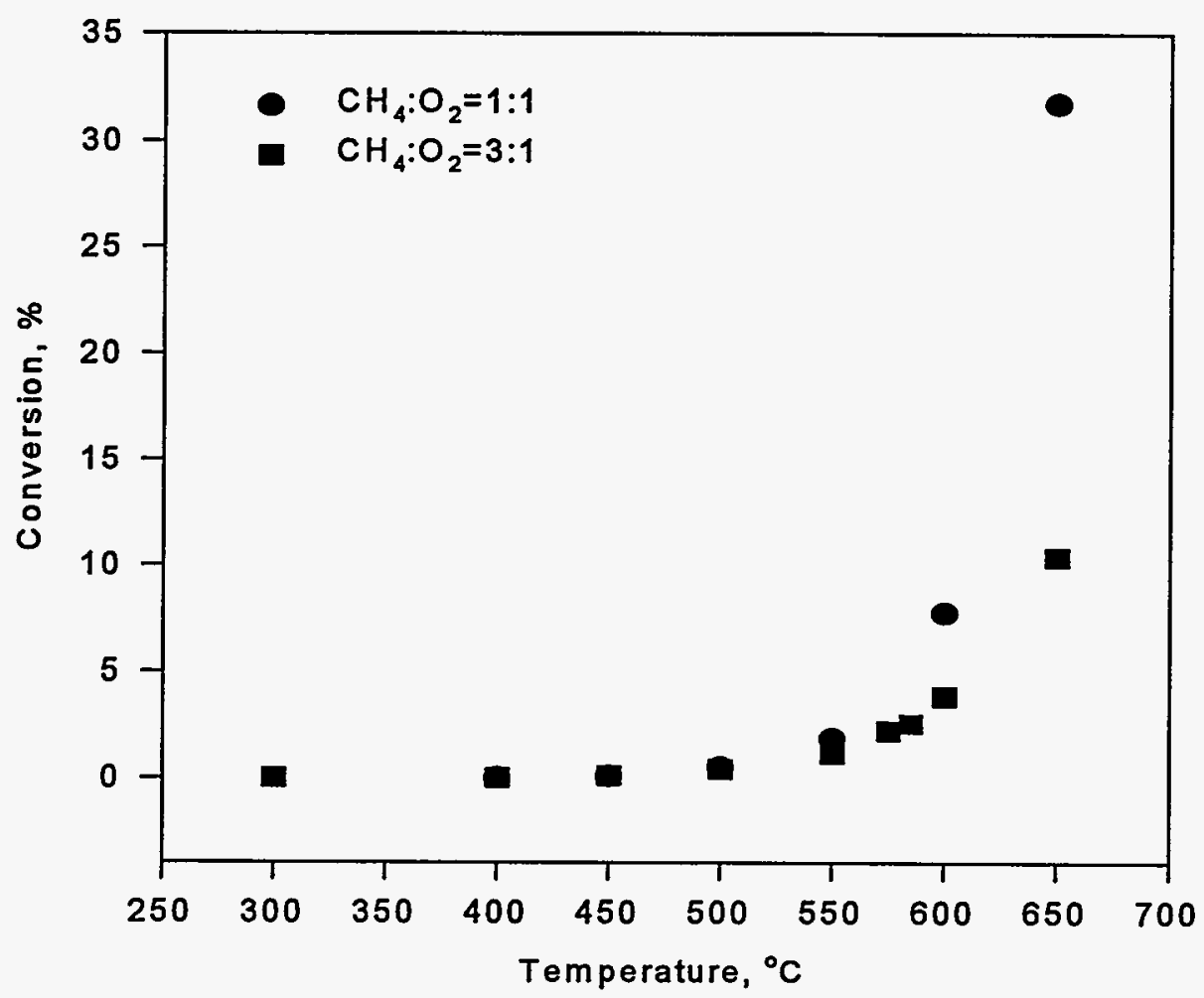

Figure 11. Effect of temperature on methane conversion over precipitated silica.

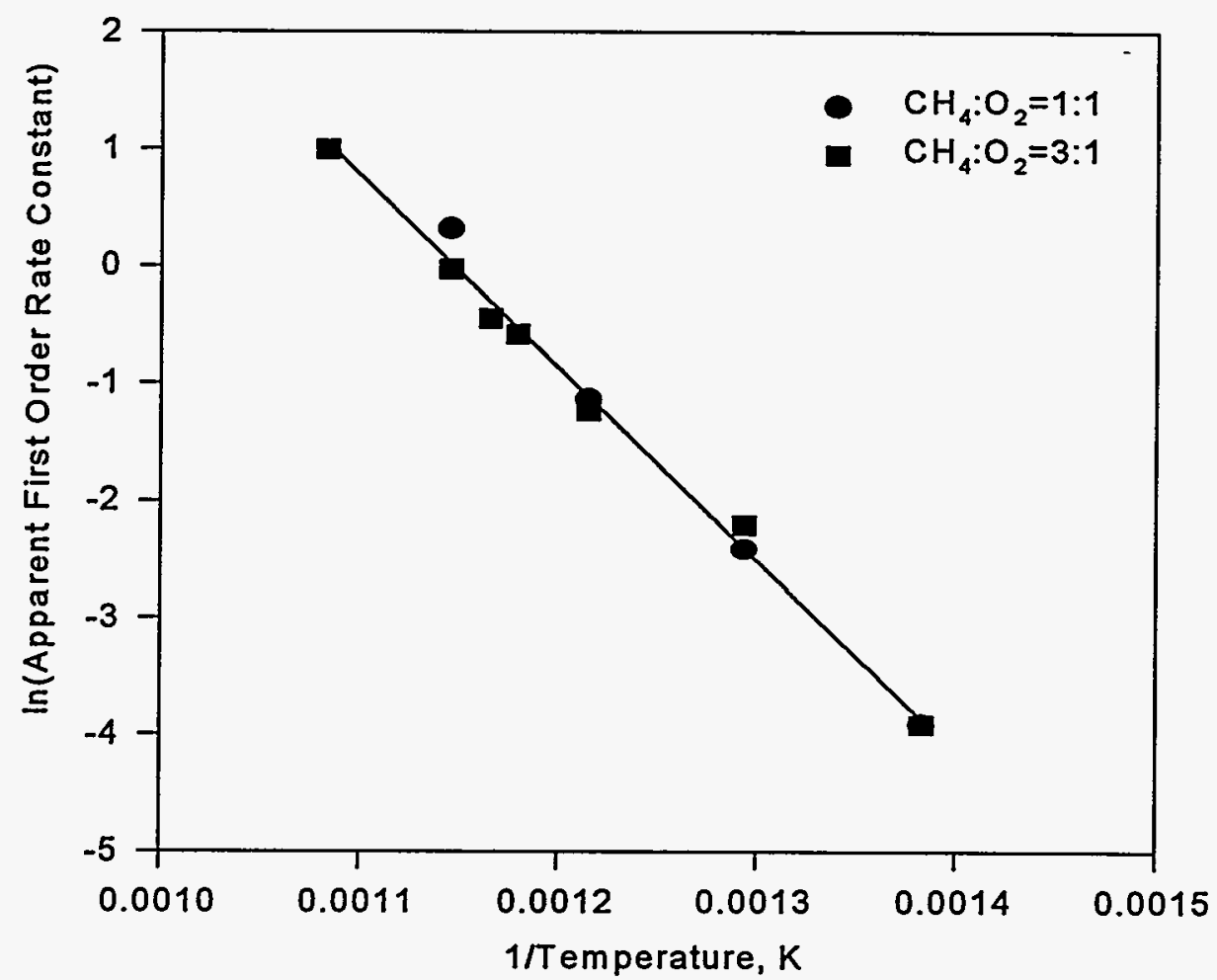

Figure 12. Arrhenius plot for methane oxidation over precipitated silica support. 

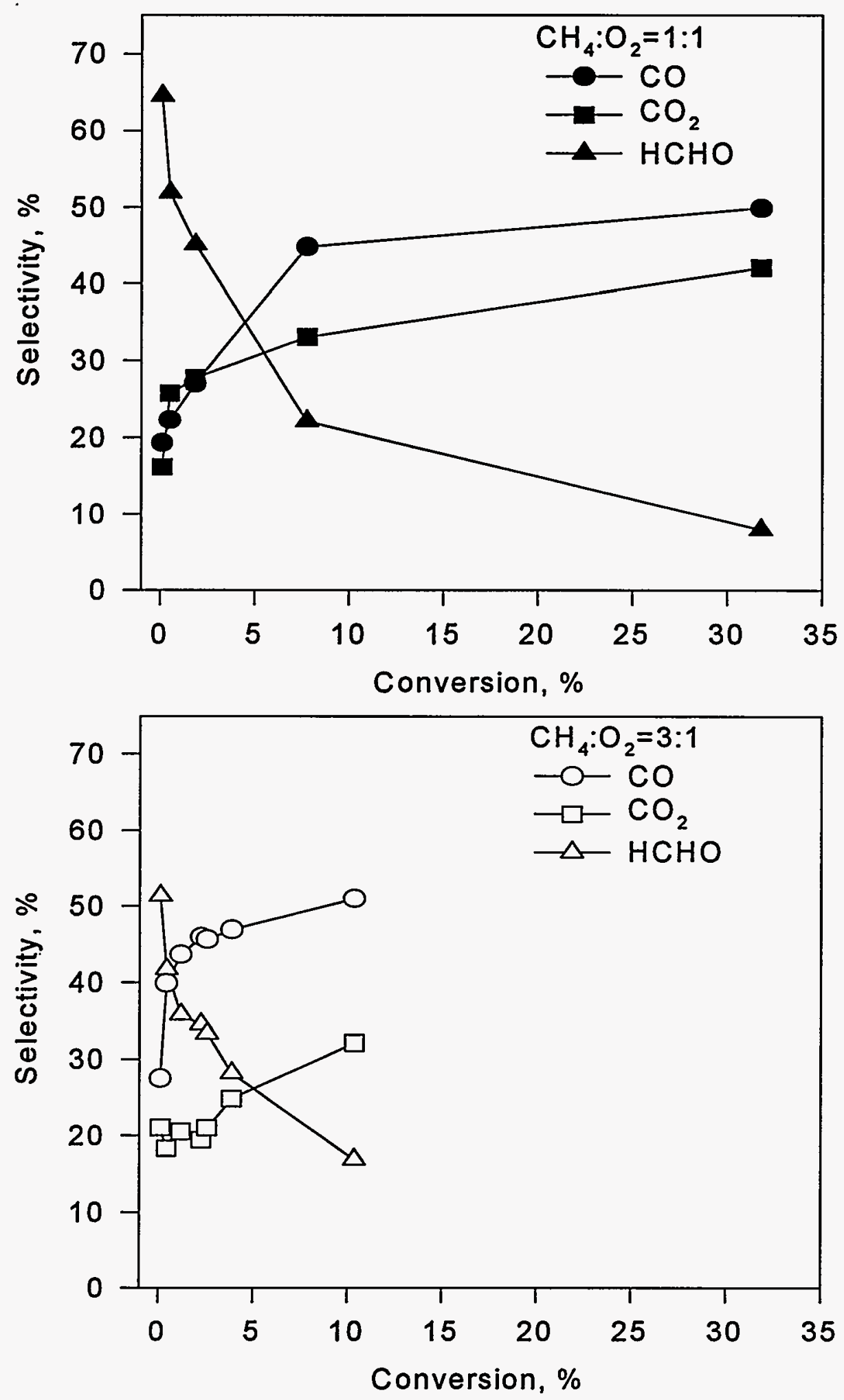

Figure 13. Selectivity as a function of conversion for methane oxidation over precipitated silica support. 


\section{PLANNED ACTIVITIES}

\section{Methane Oxidation/Vanadyl Pyrophosphate (Revisited)}

While we have acquired a great deal of data on this reaction over this catalyst, it is important to verify these results on our new gas analytical system. Thus we plan to perform a limited number of methane oxidation experiments over conventional vanadyl pyrophosphate to confirm our previous results. Additionally, there is reason to believe that inclusion of a reducing agent such as butane or another oxidant such as hydrogen peroxide would produce interesting results. These experiments will also be performed. Estimated completion date: July 1996.

\section{Methane Oxidation/Silica Supported Catalysts}

As noted, we have developed an approach to preparation of vanadyl pyrophosphate supported on silica. After confirmation that we have actually accomplished this (by XRD and Raman spectroscopy) we will perform a brief process variable study on the supported catalyst for methane oxidation. Catalytic activity of the support at high temperatures has already been measured, as reported here. We will also investigate silica supported $\mathrm{V}_{2} \mathrm{O}_{5}$ for comparison. A silica supported $\mathrm{FePO}_{4}$ has also been prepared and will be examined. Estimated completion date: July 1996.

\section{Methane Oxidation/Promoted Catalysts}

Methane oxidation results for vanadyl pyrophosphate promoted with the first row transition metals was reported last year. Several of these catalysts produced measurable but very poorly quantified amounts of formaldehyde. We plan to revisit this suite of catalysts using our new analytical approach. Estimated completion date: August 1996.

\section{Methane Oxidation/Iron Phosphate Catalysts}

Recently published results (Wang and Ostsuka, 1995) indicate that $\mathrm{FePO}_{4}$ can perform as a selective catalyst for conversion of methane to methanol if a reducing agent such as hydrogen or an oxidant such as hydrogen peroxide is included in the feed gas. We plan to investigate this approach for both $\mathrm{FePO}_{4}$ and for $\mathrm{FePO}_{4}$ on silica.

\section{Butane Oxidation}

Vanadyl pyrophosphate catalysts are used commercially for the conversion of butane to maleic anhydride by partial oxidation. We plan to perform a limited number of butane oxidation experiments to 1 ) verify that we have catalytic materials with similar properties to those reported for commercial catalysts and 2) to determine if any of the catalyst modifications we have performed have any effect on activity or 
selectivity for this well known reaction. Estimated completion data: September 1996.

\section{Publication of Results}

Up until now this project has not produced refereed publications and therefore has not been productive in the academic sense. Clearly, vanadyl pyrophosphate has not proven to be a "magic bullet" for selective methane conversion. However a number of interesting things have been observed and it is important to make this information widely available so that others do not have to retrace our steps. Thus we are currently preparing two papers for publication. The first deals with our earlier attempts to increase the surface acidity of vanadyl pyrophosphate. These experiments were directed at achieving higher activity in methane conversion and were not particularly successful in that regard. A second paper describing the kinetics of methane, methanol, and formaldehyde oxidation over vanadyl pyrophosphate is also being prepared. Both papers should be submitted in August or September 1996. 


\section{REFERENCES}

Ai, M. J. Catal. 101389 (1986).

Busca, G., Centi, G., Trifiro, F., Lorenzelli, V. J. Phys. Chem. 901337 (1986a).

Busca, G., Cavani, F., Centi, G., Trifiro, F. J. Catal. 99400 (1986b).

Busca, G., Centi, G. J. Am. Chem. Soc. 11146 (1989).

Centi, G., Trifiro, F., Ebner, J.R., Franchetti, V.M. Chem. Rev. 8855 (1988).

Horowitz, H.S., Blackstone, C.M., Sleight, A.W., Teufer, G. Appl. Catal. 38193 (1988).

Hutchings, G.J. Appl. Catal. 721 (1991).

Michalakos, P.M., Kung, M.C., Jahan, I., Kung, H.H. J. Catal. 140226 (1993).

Miyake, T., Doi, T. Appl. Catal. A: General 13143 (1995).

Parmaliana, A., Frusteri, F., Miceli, D., Mezzapica, A., Scurrell, M.S., Giordano, N. Appl. Catal. 78 L7 (1991).

Parmaliana, A., Sokolovskii, V., Miceli, D., Arena, F., Giordano, N. J. Catal. 148514 (1994).

Wang, Y., Otsuka, K. J. Catal. 155256 (1995). 